\title{
RUBBLE ROAD: UPAYA MENIADAKAN REHANDLE DI PIT BENDILI PRIMA.
}

\author{
Andi Ardianto \\ Senior Mining Engineer \\ Bintang Departement PT. Kaltim Prima Coal
}

\begin{abstract}
ABSTRAK
Rubble Road merupakan pilihan membuat jalan di floor batubara dengan metode blasting. Project ini dilakukan di floor BN, Pit Bendili Prima pada July 2019 lalu dan bertujuan membentuk jalan pengganti dari pit ke dump point. Rubble road di lakukan pada floor batubara bukan basal dengan interburden yang cukup lebar terhadap basal seamnya. Sehingga dapat dibentuk badan jalan dan terproyeksikan dinding yang lebih tegak terhadap seam floor terganggu. Berbeda dengan metode konvensional dan praktis yang kerap dilakukan, untuk mendapatkan bentuk jalan di area floor dilakukan dumping material. Tentunya ini akan berdampak pada cost tambahan ditahun mendatang. Karena overburden (ob) kbcm yang dipakai untuk construct jalan, harus digali kembali untuk mendalamkan Pit. Eksekusi rubble road ini juga melibatkan team geotek untuk assesmentnya agar stabilisasi jalan tidak menjadi kendala dimasa mendatang.
\end{abstract}

Kata kunci : rubble road, jalan pengganti, meniadakan rehandle.

\begin{abstract}
Rubble Road is an option to create a road on the coal floor by blasting method. The project was carried out on the BN floor, pit Bendili Prima in July 2019 and is intended to provide a replacement road from pit to dump point.Rubble road is carried out on a non basalt coal floor with afairly wide interburden on the basal seam.So that the road can be formed and projected a wall that is more upright against the disturbed seam floor.Unlike the conventional and practical methods that are often done, to get the shape of the road in the floor area is carried out dumping material.Surely this will have an impact on additional costs in the coming year.Due to the over burden (ob) used for road construction, it has to be dug back to deepen the pit.The execution of this road also involves the geotech team for its assessment, so that road stabilization is not an obstacle in the future.
\end{abstract}

\section{A. PENDAHULUAN}

Dalam menghadapi sequence penambangan yang dinamis, hampir selalu diikuti oleh perubahan dan konstruksi jalan tambang yang baru. Kondisi ini dimungkinkan karena, jalan yang dibentuk bukan merupakan jalan final. Namun adalah jalan temporary yang kemudian harus digali dan terus berubah seiring dengan penurunan muka pit.

Perubahan sequence dan jalan ini pun juga dihadapi di Pit Bendili Prima, PT Kaltim Prima Coal (KPC). Jalan yang ada, berada di tengah badan pit, sehingga berdampak pada luasan pit yang terbatas.Konstruksi jalan pengganti menjadi hal yang penting dilakukan guna memperluas area kerja 
agar interaksi antara digger tetap aman dan produktif. Selain itu batubara di area jalan existing merupakan bagian rencana coal ekspose di bulan Agustus 2019 ,sehingga jalan yang ada memang harus digali dan diputus.

Tabel 1. Allokasi digger di Pit Bendili Prima F2 June 2019

\begin{tabular}{|c|c|c|c|c|c|c|c|c|c|}
\hline \multirow{2}{*}{\multicolumn{2}{|c|}{1000}} & Jun-19 & Jul-19 & Aug-19 & Sep-19 & Oct-19 & Nov-19 & Dec-19 & 2019 \\
\hline & & 30 & 31 & 31 & 30 & 31 & 30 & 31 & 365 \\
\hline \multicolumn{10}{|c|}{ KPC SHOVEL ALLOCATION } \\
\hline \multicolumn{10}{|c|}{ F2 June Forecast 2019} \\
\hline BENDILI PRIMA (North) & $\mathbf{s} 323$ & 1 & 1 & 1 & 1 & 1 & 1 & 1 & 1 \\
\hline & $\mathbf{s 3 2 4}$ & 1 & 1 & 1 & 1 & 1 & 1 & 1 & 1 \\
\hline & 5402 & 1 & 1 & 1 & 1 & 1 & 1 & 1 & 1 \\
\hline & s405 & & & & & & & & \\
\hline & $\mathbf{s 4 0 8}$ & & & & & & & & \\
\hline & $s 409$ & 1 & 1 & 1 & 1 & 0 & o & o & \\
\hline & $\mathbf{s 4 1 3}$ & & & & & & & 1 & 1 \\
\hline & $s 415$ & & & & 1 & 1 & 1 & 1 & 1 \\
\hline & 5601 & 1 & 1 & 1 & 1 & 1 & 1 & 1 & 1 \\
\hline & $\mathbf{s 6 0 2}$ & & & & & & & & \\
\hline & $70 T A$ & & & & & & & & 6 \\
\hline
\end{tabular}

Terdapat 5 digger yang beroperasi di Pit Bendili Prima. Yakni : dua unit Hitachi Ex 3600 B, satu unit Liebherr R 966S, satu unit Liebherr R966B dan satu unit Liebherr R9800. Selain unit Liebherr R966S, semua unit lainnya berada di Bendili Prima bawah, dengan elevasi muka pit terdalam pada july 2019 adalah RL-120. Area Bendili Prima bawah ini yang terdampak dengan adanya jalan ditengah badan pit.

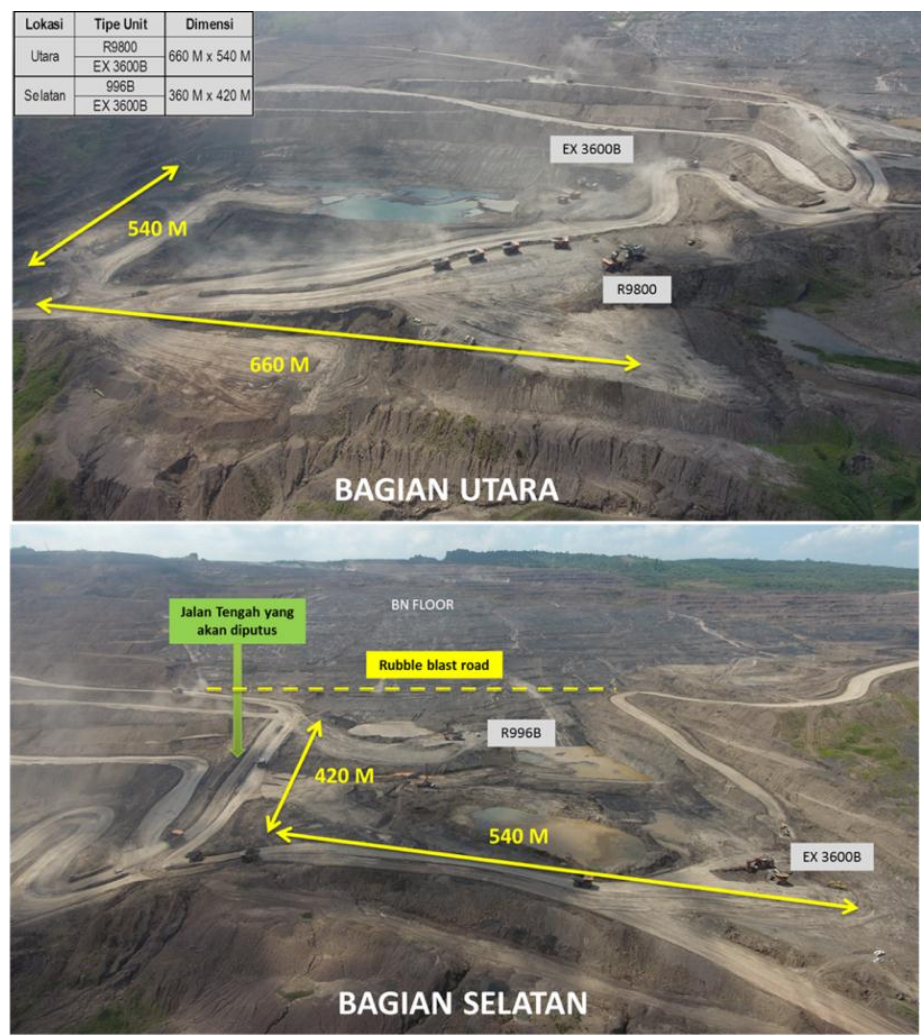

Gambar 1. Rona awal Bendili Prima bawah pada EO June 2019

Pada akhir juni 2019, Pit Bendili Prima bawah memiliki dimensi di bagian utara : $660 \mathrm{~m}$ x $540 \mathrm{~m}$. Sedangkan di bagian selatan memiliki dimensi : $360 \mathrm{~m}$ x $420 \mathrm{~m}$. Kedua bagian area tersebut ditempati oleh masing masing 2 digger.Dengan adanya jalan tengah yang membagi Bendili Prima bawah menjadi dua bagian : utara-selatan, menyebabkan area kerja empat digger tersebut menjadi sempit. Hal ini bila 
terus diabaikan akan berpengaruh pada terganggunya continuitas produktifitas kerja unit dan berpotensi kondisi tidak aman.

Berdasarkan technical handbook Mining Operation Division (MOD) KPC dan MOD Supervisor Pocket Book, ditetapkan bahwa dimensi loading point standart untuk double front loading pada R996B adalah memiliki lebar minimum $30 \mathrm{~m}$ dan panjang $140 \mathrm{~m}$.

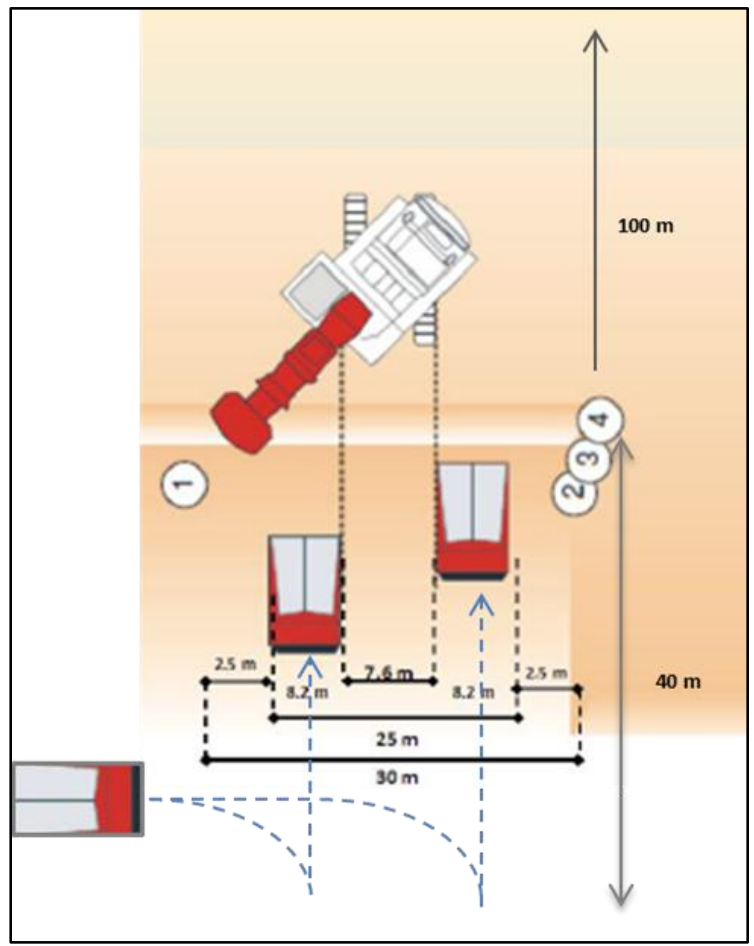

Gambar 2. Double front loading pada R966B

Pada Juli 2019, Pit Bendili Prima memiliki target rencana coal eksposed sebesar 222 kt. Batubara di area jalan existing merupakan bagian rencana coal ekspose di bulan Juli 2019 , sehingga jalan yang ada memang harus digali dan diputus.

Tabel 2. Total Rencana Coal Ekspose Pit Bendili Prima pada Juli 2019

\begin{tabular}{|l|c|r|}
\hline BENDILI PRIMA & & \multicolumn{1}{c|}{ Jul } \\
\hline & & \\
\hline OB Removed & $\mathrm{kBCM}$ & 3877 \\
\hline Coal Exposed & $\mathrm{kt}$ & 222 \\
\hline S.R. & $\mathrm{BCM} / \mathrm{t}$ & 17.5 \\
\hline
\end{tabular}

Macam seam batubara yang akan diperoleh dari menggali balik jalan existing adalah BN-60, BN-70 dan B2-70. Total tonase yang diperoleh dari ekspose seam seam tsb adalah 108,279 ton, yang merupakan separuh dari target coal yang harus dicapai di bulan Juli 2019. Sedangkan total overburden (ob) yang harus digali adalah $1,894,883 \mathrm{bcm}$ 


\section{B. METODOLOGI}

Dalam konstruksi jalan di floor, umum dilakukan dumping material. Cara ini terlihat efektif, karena pada saat konstruksi dapat dilakukan dumping dekat. Namun cara ini sebenarnya menimbulkan masalah diwaktu mendatang. Karena ob yang didumping akan digali kembali di masa mendatang.Untuk mengetahui besaran ob yang yang didumping, dibuat design perbandingan, Design pertama adalah design jalan dengan timbunan dan design berikutnya adalah design rubble road.

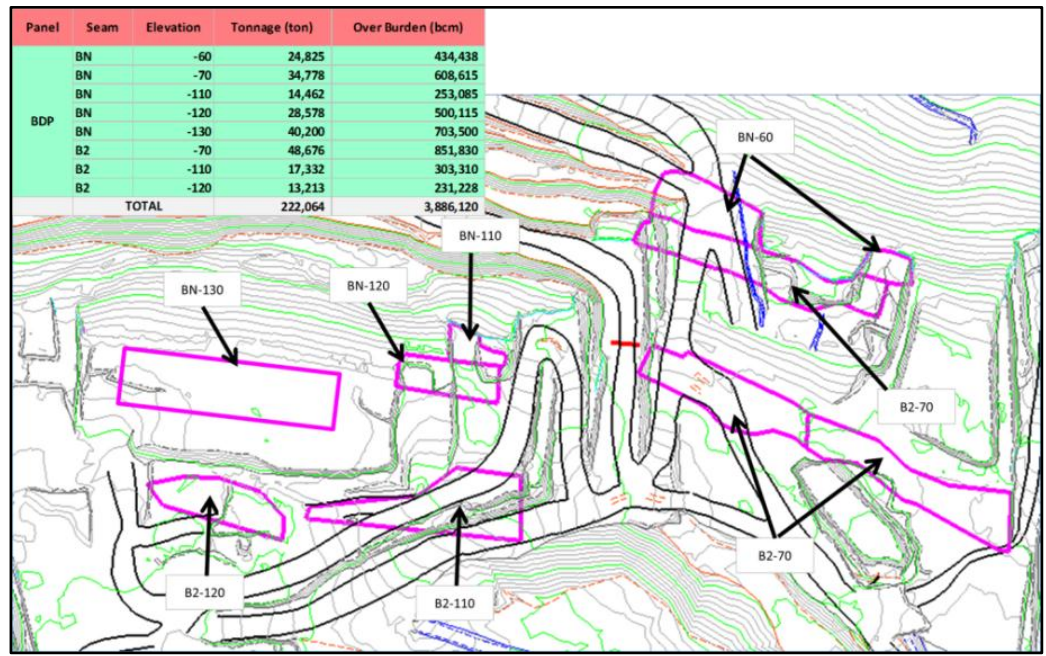

Gambar 3. Rencana Coal Ekspose Pit Bendili Prima pada Juli 2019
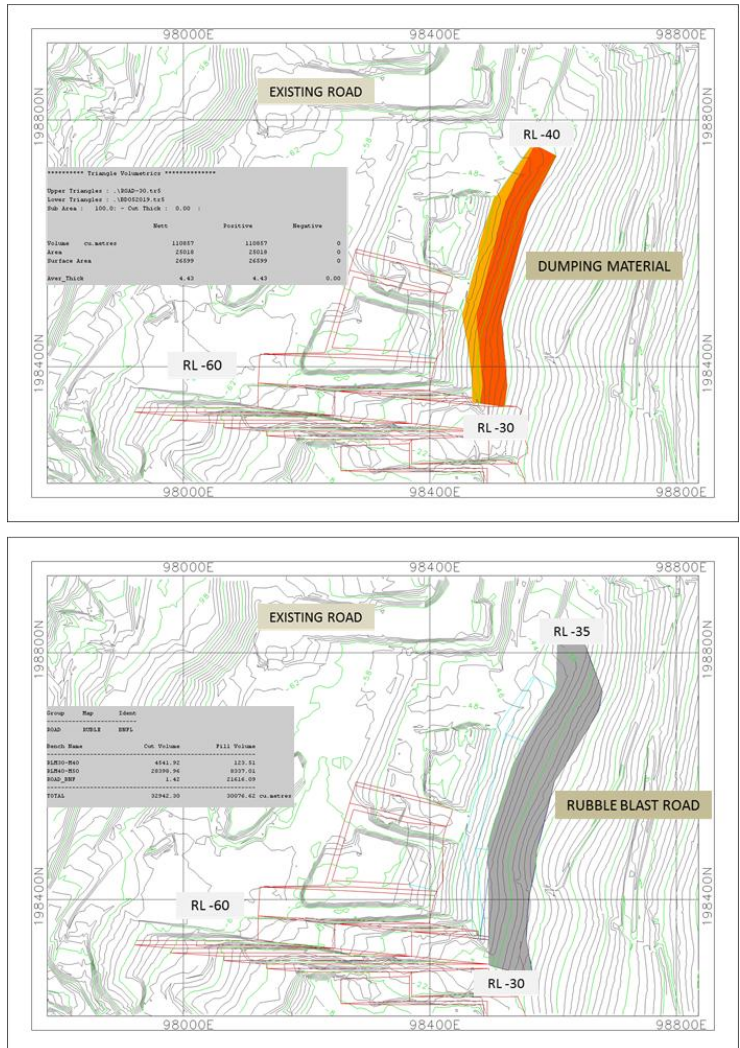

Gambar 4. Jalan pengganti di floor BN 


\section{B.1. Dumping Material}

Dalam project dumping material, dibutuhkan $110,857 \mathrm{bcm}$ untuk membuat jalan pengganti. Cycle time (CT) yang di perlukan untuk dumping di area ini adalah 14 menit. Sedangkan rubble blast road tidak ada material tambahan dan cycle time yang dibutuhkan adalah 19.53 menit karena direncanakan untuk dumping di inpit dump RL-10 dengan kapasitas 239,000 bcm.

Tabel 3. Durasi pengerjaan dump material ke jalan pengganti

\begin{tabular}{|c|c|c|c|}
\hline & \multicolumn{2}{|c|}{ Project Name } & \\
\hline Truck & Dump to Road & Inpit dump RL-10 & \\
\hline Distance one way (meter) & 1,207 & 1,684 & \\
\hline Cycle Time (menit) & 14.00 & 19.53 & \\
\hline Kapasitas (bcm) & 110,857 & 239,000 & Cukup \\
\hline Truck Ratio & 1.09 & 1.09 & \\
\hline PA & $88 \%$ & $88 \%$ & \\
\hline US & $73 \%$ & $73 \%$ & \\
\hline Payload (ton) & 290 & 290 & \\
\hline Truck EH4500 (unit) & 2 & 2 & \\
\hline Durasi (hari) & 6.15 & 18.49 & \\
\hline Dozer & & & \\
\hline Pushing speed (km/hr) & 3 & & \\
\hline Reverse speed $(\mathrm{km} / \mathrm{hr})$ & 6 & & \\
\hline Cycle Distance $(\mathrm{m})$ & 20 & & \\
\hline Positioning (minutes) & 0.25 & & \\
\hline Dozing time per cycle (minutes) & 7.75 & & \\
\hline Blade cap (LCM) & 22 & & \\
\hline Fill factor & 1.1 & & \\
\hline Eff. Cap (Bcm) & 20.17 & & \\
\hline Grade factor (dip $2 \%$ ) & $102 \%$ & & \\
\hline Material factor & $80 \%$ & & \\
\hline Dozing technique & $100 \%$ & & \\
\hline Operator & $80 \%$ & & \\
\hline Weight correction & $87 \%$ & & \\
\hline Total Correction factor & $57 \%$ & & \\
\hline $\mathrm{PA}$ & $85 \%$ & & \\
\hline US & $75 \%$ & & \\
\hline Productivity (bcm/hour) & 88.67 & & \\
\hline Dozing Cap/day & 1,357 & & \\
\hline Material need to dozing $(\mathrm{bcm})$ & 11,086 & & \\
\hline Total Durasi Pengerjaan (day) & 14 & & \\
\hline
\end{tabular}

Selama melakukan penimbunan selama 14 hari, pada rencana jalan pengganti diperoleh cycle time 14 menit. Pengaruh cycle time rendah ini terhadap plan forecast di bulan Juli dapat dijabarkan pada Tabel 4 berikut

Tabel 4. Pengaruh cycle time rendah terhadap plan Forecast, Juli 2019

\begin{tabular}{|c|c|c|c|c|c|}
\hline \multicolumn{2}{|c|}{ Cycle Time Juli 2019} & DUMP & PLAN & DUMP & PLAN \\
\hline Dump Location & Elevation & \multirow{2}{*}{\multicolumn{2}{|c|}{$2109 \quad 2109$}} & \multirow[b]{2}{*}{37.44} & \multirow[b]{2}{*}{37.44} \\
\hline AB VOID & RL170 - RL100 & & & & \\
\hline MPT BPR DUMP & BL250-RL240 & 2,279 & 2,279 & 22.45 & 22.45 \\
\hline INPIT BPR DUMP & RLO - RL-10 & 81 & 81 & 14.00 & 19.53 \\
\hline INPIT BPR DUMP & RL-10 - RL-20 & 158 & 158 & 15.05 & 19.53 \\
\hline INPIT BPR DUMP & RL-20 - RL-30 & 199 & 199 & 19.53 & 19.53 \\
\hline INPIT BPR DUMP & RL-30 - RL-40 & 39 & 39 & 19.53 & 19.53 \\
\hline INPIT BPR DUMP & RL-40 - RL-50 & 49 & 49 & 19.53 & 19.53 \\
\hline INPIT BPR DUMP & RL-50 - RL-60 & 41 & 41 & 19.53 & 19.53 \\
\hline INPIT BPR DUMP & RL-60 - RL-70 & 61 & 61 & 19.53 & 19.53 \\
\hline INPIT BPR DUMP & RL-70 - RL-80 & 359 & 359 & 19.53 & 19.53 \\
\hline INPIT BPR DUMP & RL-80 - RL-90 & 535 & 535 & 15.15 & 15.15 \\
\hline \multicolumn{4}{|c|}{ Grand Total } & 27.77 & 28.13 \\
\hline
\end{tabular}


Berdasarkan sequence penambangan di tahun 2021, pit Bendili Prima atas akan sampai di RL-30 pada May 2021. Pendalaman muka pit ini akan berdampak pada tergalinya kembali material yang didumping untuk project jalan pengganti ini. Berarti terdapat $110,857 \mathrm{bcm}$ yang akan menjadi cost rehandle di tahun 2021.

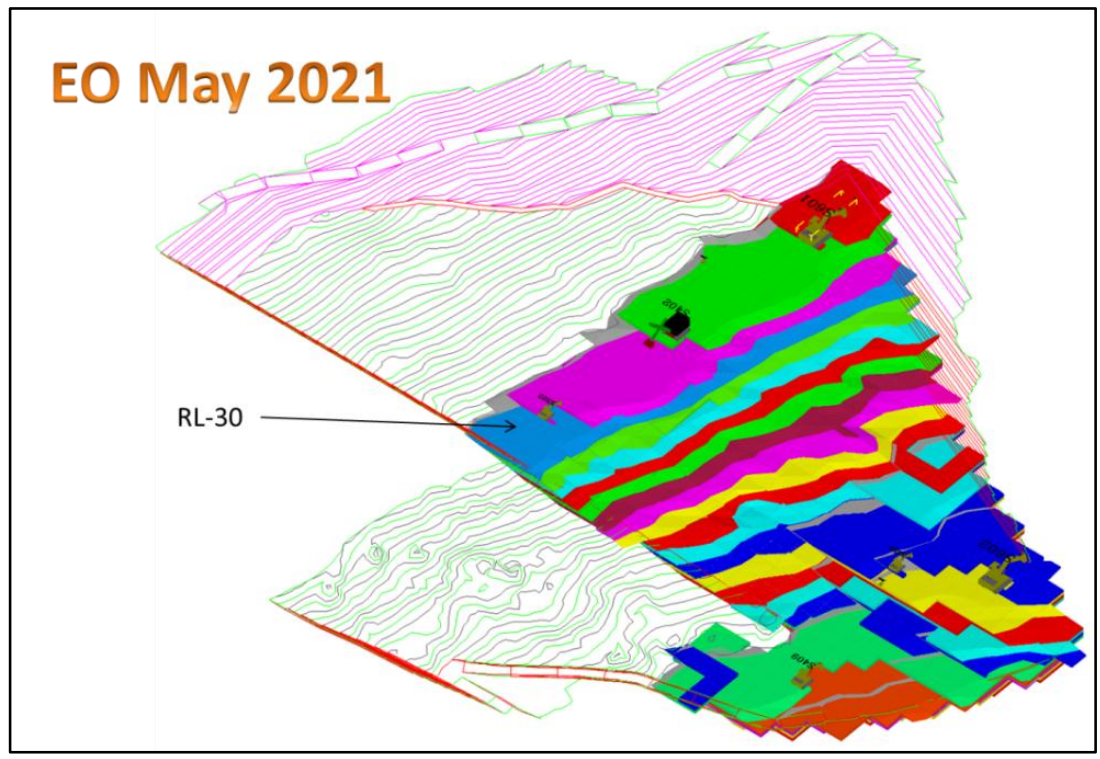

Gambar 5. Bendili Prima pada EO May 2021

\section{B.2. Rubble Road}

Pada definisinya adalah membuat jalan di floor batubara dengan bantuan metode peledakan. Opsi ini bisa dilakukan pada area floor dengan interburden yang lebar dari seam batubara berikutnya, sehingga terhindar dari praktek undercut yang dapat berpotensi terjadinya gagal stabil atau longsoran. Umumnya dilakukan dengan pemboran dan peledakan dengan lubang dangkal $1.5 \mathrm{~m}-11 \mathrm{~m}$ dengan isian bahan peledak mulai dari $1.2 \mathrm{~m}-6.8 \mathrm{~m}$, dan selebihnya adalah steaming tanpa decking.

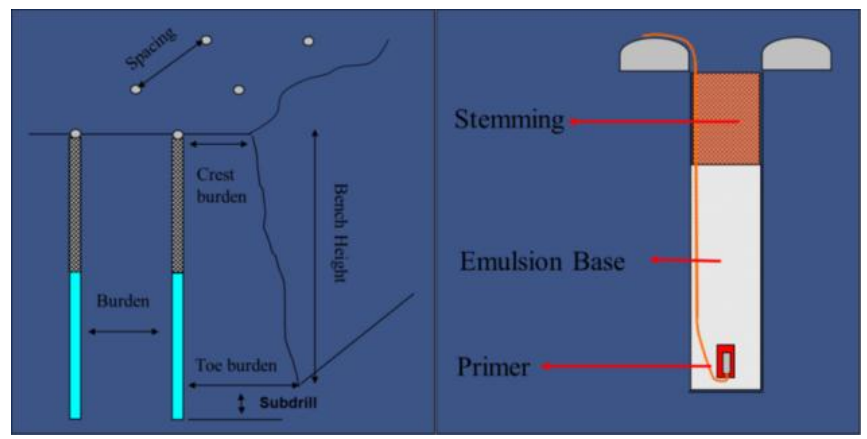

Gambar 6. Sketsa lubang ledak

Hasil dari pemboran dan peledakan ini mengacu pada bentuk design jalan yang sudah di assessment sebelumnya oleh team Geotechnical KPC. Untuk hasil analisa kestabilan adalah didapatkan nilai indikasi kestabilan dengan FOS > 1.2. 


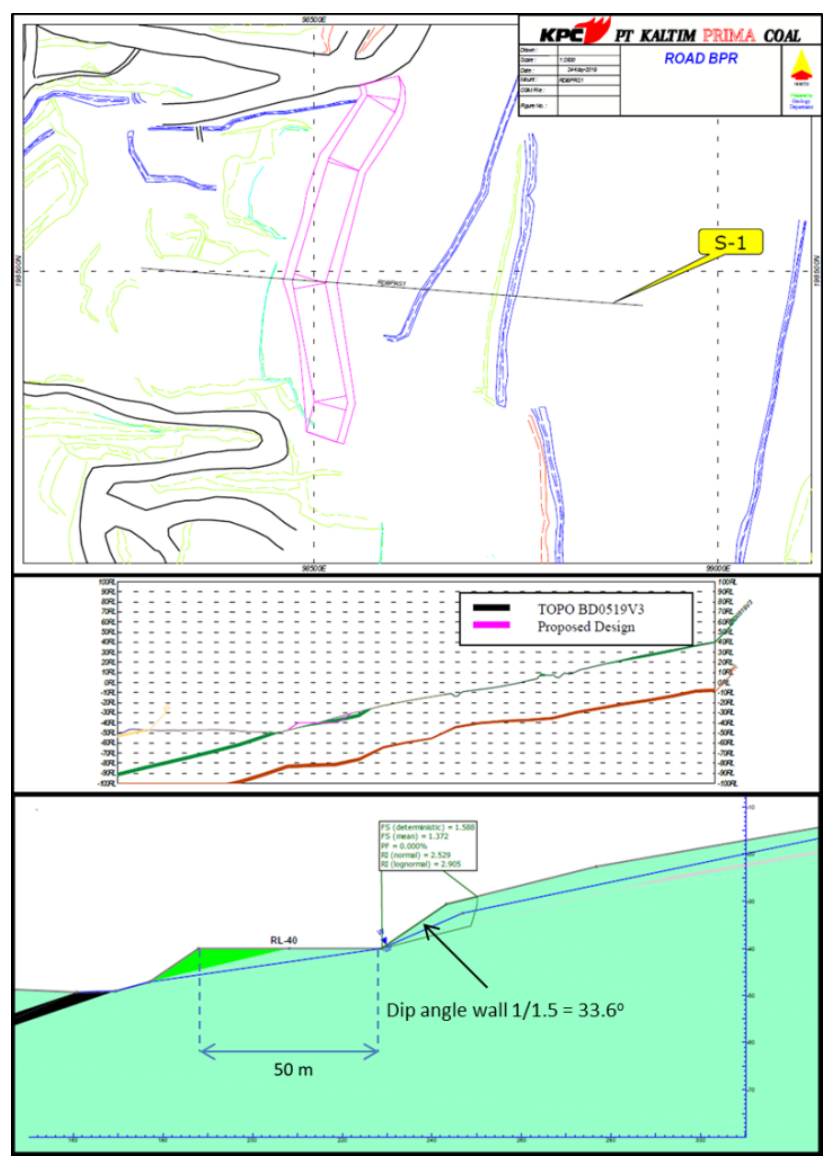

Gambar 7. Analisa kestabilan design rubble road dengan FOS $>1.2$.

Dalam mengeksekusi rubble road ini tanpa melibatkan digger ekspose. Unit auxiliary yang digunakan adalah 1 x PC 800 dan 1 x Dozer. PC 800 bertugas untuk membentuk dinding dengan kelandaian 1 : 1.5 dan tumpukan materialnya didorong dozer untuk membentuk badan jalan. Dengan kombinasi dua unit tsb, penyelesaian project ini berlangsung selama 21 hari.

Tabel 5. Durasi pengerjaan rubble road

\begin{tabular}{|c|c|c|c|}
\hline & & Dozer & \\
\hline & & Pushing speed (km/hr) & 3 \\
\hline & & Reverse speed (km/hr) & 6 \\
\hline & & Cycle Distance (m) & 20 \\
\hline & & Positioning (minutes) & 0.25 \\
\hline & & Dozing time per cycle (minutes) & 7.75 \\
\hline & & Blade cap (LCM) & 22 \\
\hline & & Fill factor & 1.1 \\
\hline & Project Name & Eff. Cap (Bcm) & 20.17 \\
\hline PC 800 & Rubble blast Road & Grade factor (dip $2 \%$ ) & $102 \%$ \\
\hline Material volume $(\mathrm{bcm})$ & 32,942 & Material factor & $80 \%$ \\
\hline Material need to cut (bcm) & 16,471 & Dozing technique & $100 \%$ \\
\hline PA & $87 \%$ & Operator & $80 \%$ \\
\hline Usage & $46 \%$ & Weight correction & $87 \%$ \\
\hline Bucket Capacity (LCM) & 6 & Total Correction factor & $57 \%$ \\
\hline Fill factor & 1.1 & $\mathrm{PA}$ & $85 \%$ \\
\hline Eff. Cap (Bcm) & 6 & Us & $75 \%$ \\
\hline Loading cycle (detik) & 22 & Productivity (bcm/hour) & 88.67 \\
\hline Productivity (bcm/hour) & 900 & Dozing Cap/day & 1,357 \\
\hline Durasi (hari) & 18.30 & Material need to dozing (bcm) & 3,008 \\
\hline & & Total Durasi Pengerjaan (day) & 21 \\
\hline
\end{tabular}


Konstruksi jalan dengan dumping material ataupun rubble road berfungsi sebagai jalan pengganti untuk ekspose batubara. Adapun nilai perolehan dari mengeksekusi jalan existing adalah sebagai berikut.

Tabel 6. Cost review dump material road

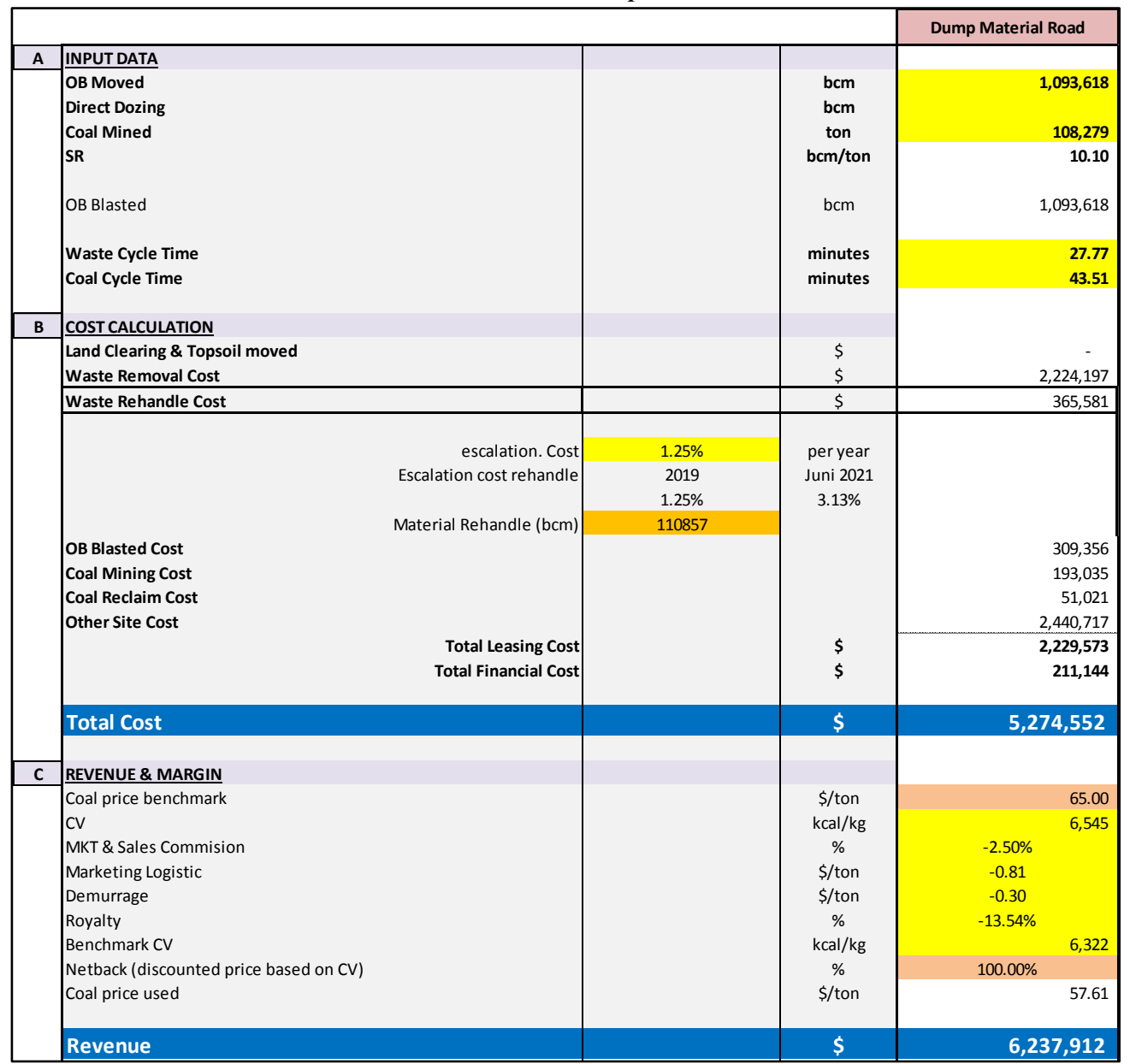

Pada dump material road, didapatkan angka cycle time yang lebih rendah dari budget, yakni 0.36 menit. Namun gain angka cycle time ini tidak mampu meningkatkan revenue secara signifikan. Timbul biaya lain dari proyeksi rehandle cost pada Juni 2021 sebesar \$ 365,581 yang membuat nilai total cost menjadi \$ 5,274,452. Berbeda dengan project rubble road, yang diawal pengerjaan mendapatkan tambahan biaya blasting. Sehingga meningkatkan waste removal cost menjadi \$2,239,180. Namun penambahan ob blasted masih memberikan kontribusi yang lebih baik daripada dengan dilakukannya road dump rehandle material. Terdapat selisih revenue positif \$ 75,619 untuk rubble road. 
Tabel 7. Cost review rubble road

\begin{tabular}{|c|c|c|c|c|}
\hline & & & & Rubble Road \\
\hline \multirow[t]{7}{*}{$\mathbf{A}$} & INPUT DATA & & & \\
\hline & OB Moved & & bcm & $1,093,618$ \\
\hline & Coal Mined & & ton & 108,279 \\
\hline & SR & & bcm/ton & 10.10 \\
\hline & OB Blasted & & $\mathrm{bcm}$ & $1,156,637$ \\
\hline & Waste Cycle Time & & minutes & 28.13 \\
\hline & Coal Cycle Time & & minutes & 43.51 \\
\hline \multirow[t]{14}{*}{ B } & COST CALCULATION & & & \\
\hline & Land Clearing \& Topsoil moved & & $\$$ & - \\
\hline & Waste Removal Cost & & $\$$ & $2,239,180$ \\
\hline & Waste Rehandle Cost & & $\$$ & - \\
\hline & \multirow{9}{*}{$\begin{array}{l}\text { OB Blasted Cost } \\
\text { Coal Mining Cost } \\
\text { Coal Reclaim Cost } \\
\text { Other Site Cost }\end{array}$} & $1.25 \%$ & peryear & \\
\hline & & 2019 & Juni 2021 & \\
\hline & & $1.25 \%$ & $3.13 \%$ & \\
\hline & & 0 & & \\
\hline & & & & 327,182 \\
\hline & & & & 52,767 \\
\hline & & & & $2,440,717$ \\
\hline & & & $\$$ & $2,229,573$ \\
\hline & & & $\$$ & 211,144 \\
\hline & Total Cost & & $\$$ & $4,925,544$ \\
\hline \multirow[t]{11}{*}{ C } & REVENUE \& MARGIN & & & \\
\hline & Coal price benchmark & & \$/ton & 65.00 \\
\hline & $\begin{array}{l}\text { CV } \\
\text { MKT \& Sales Commision }\end{array}$ & & $\mathrm{kcal} / \mathrm{kg}$ & 6,626 \\
\hline & MKT \& Sales Commision & & $\%$ & $-2.50 \%$ \\
\hline & Marketing Logistic & & $\$ /$ ton & -0.81 \\
\hline & Demurrage & & $\$ /$ ton & -0.30 \\
\hline & Royalty & & $\%$ & $-13.54 \%$ \\
\hline & \multirow{2}{*}{$\begin{array}{l}\text { Benchmark CV } \\
\text { Netback (discounted price based on CV) }\end{array}$} & & $\mathrm{kcal} / \mathrm{kg}$ & 6,322 \\
\hline & & & $\%$ & $100.00 \%$ \\
\hline & Coal price used & & \$/ton & 58.31 \\
\hline & Revenue & & $\$$ & $6,313,531$ \\
\hline
\end{tabular}
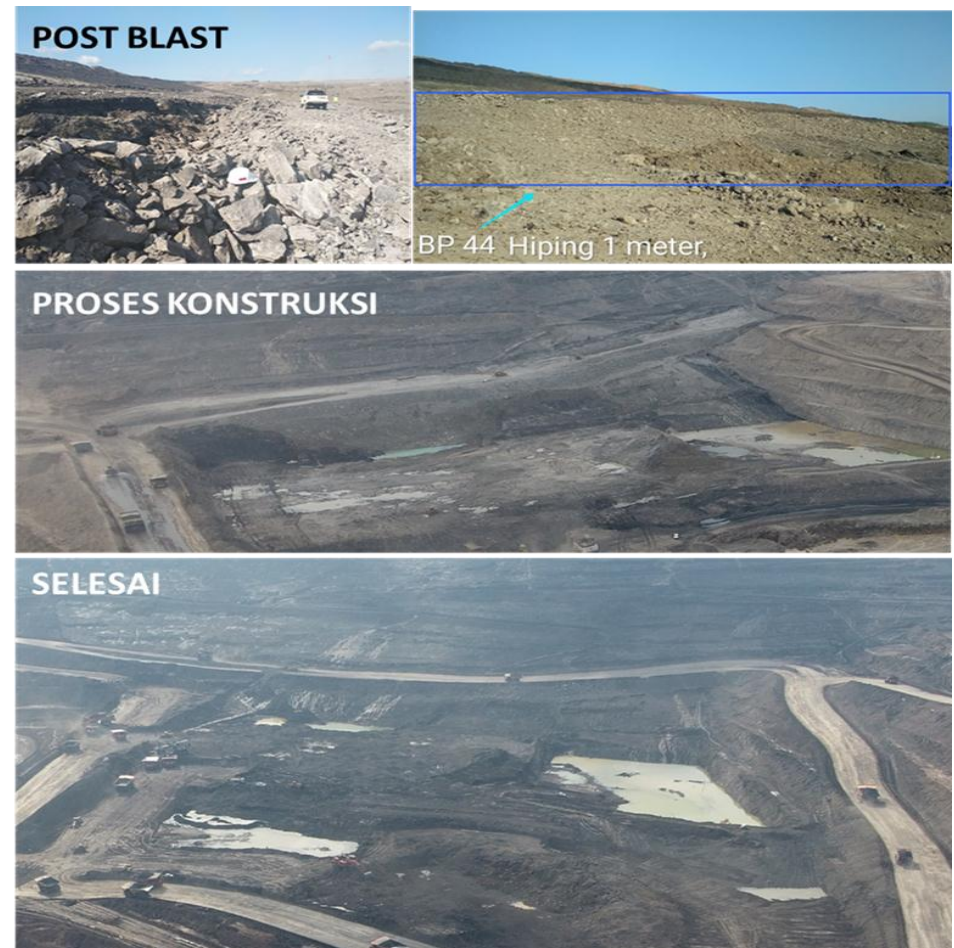

Gambar 8.Kegiatan konstruksi rubble road 


\section{KESIMPULAN}

Berdasarkan pembahasan, dapat simpulkan bahwa eksekusi rubble road memiliki nilai cost yang lebih kecil dari opsi dumping material yang umum dilakukan.Penurunan angka cycle time terhadap budget selama eksekusi dump material di badan jalan tidak serta merta menambah besar revenue. Bahkan terdapat cost tambahan akibat rehandle material yan terproyeksi dilakukan pada Juni 2021.

Rubble road bisa menjadi pilihan untuk konstruksi badan jalan di area floor tanpa rehandle, yakni dengan mengkombinasikannya dengan metode blasting. Terutama untuk area dengan interburden yang lebar semisal BN Floor terhadap seam PR. Sehingga eksekusinya tidak akan menggangu perlapisan batubara lanjutan dan berpotensi ketidakstabilan.

\section{DAFTAR PUSTAKA}

PT Kaltim Prima Coal. (2018). SOP loading di alat muat (digger). Sangatta

PT Kaltim Prima Coal. (2019). Digger allocation F2 June 2019. Sangatta

PT Kaltim Prima Coal. (2017). Technical handbook MOD_first edition. Sangatta

PT Kaltim Prima Coal (2017). MOD supervisor pocket book. Sangatta

PT Kaltim Prima Coal (2019). Equipment major minor F3 FCast v4.6_Pass \#10_R2_sent to Pits_190212. Sangatta

PT Kaltim Prima Coal (2019). BDP_Physical_F2JUNE_SentToMO_190619. Sangatta 